\title{
PELLE SUB AGNINA LATITAT MENS SAEPE LUPINA. COPYRIGHT IN THE MARKETPLACE
}

\author{
Giovanni B. Ramello
}

\section{Introduction}

The question of intellectual property and incentives for invention and creation is one that has arisen repeatedly in the history of economic thought ${ }^{1}$. However in recent decades it has developed in new directions that have attracted particular attention. More specifically, the formulation of the concept of innovation as a public good, introduced by Schumpeter (1943) and supported by the empirical findings of Solow (1957), launched a flourishing body of literature that has sought to justify intellectual property rights as an essential-though admittedly imperfect (Arrow, 1962)--tool for stimulating technological progress. The present contribution focuses on one specific type of intellectual property right, namely author's right or copyright (the two terms shall here be used synonymously ${ }^{2}$ ), which has today taken on a primary role in economic systems ${ }^{3}$.

Nevertheless the application of economic analysis to copyright is important not just for the purposes of measuring economic flows, but also for evaluating how the right can influence the structure of the market, the behaviours adopted by economic agents and the resultant competitive outcomes. This, essentially, is the approach that has been taken in this article.

In the following sections we shall focus in particular on the relationship between the right's aims of providing an incentive for creative activities, and the overall efficiency. It can in fact be shown that, even if the commodification of intellectual works by means of copyright does provide some incentive for creative activities, this benefit is offset by certain 'side effects' on the diversity and quality of the ideas produced, and interference with access to information and the incremental process of creation. All of which, if duly taken into account, can seriously call into question the overall balance of efficiency.

In the present-day debate, the justifications given for copyright and author's rights invoke both considerations of economic efficiency, as well as ethics and rhetoric. However such arguments neglect to factor in the social costs, thus portraying in false light an institution that has, in practice, often served private interests very distant from its purported aims, injecting a 
significant amount of inefficiency into the economic system. This state of affairs can therefore be aptly summed up by the Latin adage of the title: "A wolf often lies concealed in the skin of a lamb".

Nevertheless, the objections raised thus far, in the literature on the economic analysis of intellectual property rights, have inevitably resorted to the contraposition of extra-economic values, such as equity and justice, against those of economic efficiency. In the present discussion we shall seek to reconcile these two sides, showing how, under an expanded analytical perspective with respect to costs and benefits, and taking into consideration additional elements, copyright proves to be fundamentally inefficient even from a strictly economic standpoint, and that this will only be aggravated by technological progress ${ }^{4}$. We will therefore demonstrate that an examination of the dynamics of the right within the market and society can seriously call into question, or even entirely overturn, the traditional economic arguments in favour of copyright.

\section{The traditional law and economics analysis}

The standard justification for copyright (and intellectual property rights in general) is based essentially on the hypothesis that the legal institution emerged in response to a market failure, because in the absence of such a right individuals would not have an adequate incentive to undertake the creation of new (expressions of) ideas ${ }^{5}$. The argument sends back to the theory of public goods and externalities, which Coase (1960) resolved through the attribution of property rights to individuals. These, as the outcome of a negotiation between economic agents (and in the absence of subsequent public intervention) make it possible, at least in the original model, to achieve an optimal equilibrium in the Paretian sense ${ }^{6}$.

The central assumption behind this approach is therefore that an appropriability problem exists which, in the absence of an adequate system of incentives, would result in a sub-optimal level of new ideas being produced ${ }^{7}$. In other words, the non-rival consumption and low marginal costs of dissemination/reproduction of copyrighted works, set against their high fixed production costs, leads to free-riding behaviours that have a negative impact on investments. Therefore, in the absence of an appropriate mechanism--i.e. provision for adequate incentives-the above-described situation can, in the extreme case, produce adverse selection phenomena and drastically reduce the numbers of those who undertake creative activities ${ }^{8}$.

The above is not a universally accepted view, and has been repeatedly challenged by various authors ${ }^{9}$. However this dissent has by and large been suppressed by the vigorous lobbying of copyright stakeholders--first and foremost among these the content-producing multinationals-which has today prevailed in shaping the law making process (Christie, 1995; Ryan, 1998). 
In the final analysis, therefore, the most substantiated arguments in favour of intellectual property rights rest on the two-fold thesis of a legal monopoly as an "incentive to create" and/or as an "incentive to disclose".

In the first case, the monopoly profits secured through the exclusive right are necessary for fuelling creative activities. In the second case, the temporary revenues from the exclusive right help stimulate the disclosure of new ideas that would otherwise, due to disinterest or fear of appropriation by others, fail to be disclosed (Audretsch, 1997). The static inefficiency arising from the intellectual property right monopolies is thus remedied through a dynamic efficiency, i.e. the creation an optimal level of new copyrightable works over time ${ }^{10}$. We note, however, that the public objective is not merely to promote the production of new expressions of ideas, but rather to attain a general enrichment of knowledge--which is by nature collective and public. And for this reason copyright is not an absolute right, but on the contrary limited in duration, and in certain cases subject to derogation (Gordon and Bone, 1999; Bently and Sherman, 2001).

The above-described position relies heavily on the assumption that intellectual property rights have virtuous effects on scientific and cultural development, but neglects to consider that "the familiar devices for protection of intellectual property are known to have a variety of untoward side-effects that may distort and even impede the progress of technology" (David, 1993, p.17) ${ }^{11}$. These side-effects in fact influence the dynamic efficiency and substantially alter the final balance, as we shall see below.

For now, it should be clear that the underlying premise invoked by supporters of intellectual property rights is that this system can achieve the goal of maximising the net social surplus, to produce an optimal quantity and quality of information. This point is crucial for the economic analysis of copyright.

\section{Incentives and value}

Upholders of intellectual property thus resolve the problem of the optimal production of a public good (information and knowledge in general) through its ex-lege transformation into a private good. This solution effectively rests upon the (by no means obvious) assumption that it is possible to reconcile the often dialectically opposed camps of private and the public interests. Only a careful and detailed analysis can reveal, for each particular case, whether these two spheres share any common ground that might enable them to enter into a virtuous relationship.

\subsection{Ideas and externalities}

From this perspective, the first question to address hinges on the conversion of intellectual works into commodities, i.e. their transfer from the cultural to the commercial sphere, a 
metamorphosis that underpins the functioning of the market. However this transition implies a difficult reconciliation between the 'use-value' that society attributes to cultural products ${ }^{12}$ and their 'exchange-value' as defined by the market ${ }^{13}$. This rift, which naturally also applies to objects other than ideas, becomes especially significant in the case of copyrightable works which, by virtue of belonging to the knowledge and information sphere, are inherently appurtenant to collective contexts. An idea cannot be attributed an exchange-value if it is devoid of use-value for a community; and, an anthropologist would say, it will have use-value for a community as a consequence of its close interrelationship with the system of values and beliefs that generated it ${ }^{14}$.

The peculiarity of intellectual property, as compared with conventional property, lies precisely in the fact that categories of the physical, measurable and divisible world are applied to the sphere of culture and knowledge, where boundaries and quantities are to some extent a legal artifice, and hence open to discussion. In fact, the margin of separation between one copyrightable work and another (unlike that separating tangible objects), is fuzzy and arbitrary; already in the 19th century, the English scholar Augustine Birrell noted that, while it is easy to draw the boundaries of a physical asset, it is altogether more arduous to determine how much a book truly belongs to an author, because any creative endeavour contracts a significant and indissoluble debt with its precursors, and with the context in which it is generated (Goldstein, 1994).

The use-value of an intellectual work is inevitably based on its semiotic content, which in its turn is inherently social in character ${ }^{15}$ : the form of the idea, i.e. its fixing in a tangible medium, will have an exchange-value due to the fact that it conveys shared symbols, in other words a use-value. And in fact the institution of the right by the political authorities is motivated by usevalue: the recurrent refrain being that ideas are socially desirable, but that in the absence of copyright they would be created--and disclosed--in suboptimal quantities, to the detriment of society.

However it is the exchange-value that underpins the incentive, and makes the attribution of exclusive economic exploitation rights attractive to an individual: in the marketplace, ownership of an idea is meaningful only when its exchange-value is high, i.e. when the legal monopoly translates into (or approximates) an economic monopoly ${ }^{16}$. So, the theory of intellectual property rights implicitly assumes that exchange-value--whose sphere of action is the market-can provide an incentive for the creation of use-value--whose sphere of action is society. This is patently not a neutral assumption, unless one admits an equivalence or perfect correlation between the use-value and exchange-value of an idea, which is by no means true in practice.

An additional consideration on this point: from an economist's perspective the situation described is particularly convenient if production of use-values is viewed as a positive 
externality, with respect to the output of a production process, which in our case is the exchange-value. Now the dilemma of policymakers lies precisely in the peculiarity that the objective being targeted is the externality, whereas the stimulus is exerted on the output, which in the intellectual property right model furnishes the sole effective incentive for creators. Therefore, if we assume a highly variable distribution of externalities between different copyrightable works, the incentive for any one particular output does not guarantee that an optimal amount of externalities will nevertheless be produced ${ }^{17}$. On the other hand it can be dangerous to rely on the market for the stimulation and selection of ideas, because this entrusts the incentive exclusively to profit--i.e. to a purely economic dimension that precludes any broader set of values. A mechanism of this type, that is only weakly aligned with its general objectives, can therefore produce results very much at odds with those for which the right was originally instituted.

In the case of patents, one can sometimes posit a degree of correlation between profits and the social value of ideas. However the claim that a particular development is the one that produces maximum welfare remains unproven, because there is generally no opportunity to make comparisons between alternative paths. On the contrary, a rich body of literature has shown that successful ideas can crowd out others due to the so-called increasing returns of adoption' (Arthur, 1988 and 1989), which tend to direct the course of subsequent developments (Foray, 1989). And in cases where a comparison can be made, it emerges that the outcome of the innovation race is not always the best one, because historical accident, demand-side network externalities, issues of compatibility with preceding standards and path-dependence can ordain the success of ideas that are actually inferior to competing ones (David, 1985 and Arthur, 1988).

In the case of copyrightable works, the question is even more vexed because their cultural and social value hinges on complex phenomena, in which the role of the market is relatively recent and not yet fully understood. We can be justified in saying, though, that its pure profitorientation makes the market ill-equipped to handle non economic variables connected with the wider social context--unless one is prepared to accept a questionable equivalence between market and society. Therefore, the only guaranteed effect of the monopoly created by copyright is that it attributes an exchange-value to the intellectual work, i.e. assigns it a market price. However this market price may be only marginally correlated with its possibly high use-value, or diverge from it completely.

\subsection{Effects on creative activities}

What can happen, on the other hand, is that the economic nature of the marketplace will mainly stimulate the creation of ideas geared to the profit maximisation objective, i.e. those with a high exchange-value, even if their use-value is questionable, while neglecting those ideas 
whose use-value cannot be fully 'comprehended' by the exchange-value. The proliferation of websites that distribute pornographic material on the Internet is one instance of the above mechanism ${ }^{18}$.

What is more, the commercial rationale that favours the types of products most successful on the market will drive creative activities to converge toward the subset of ideas that promise greatest profits, with a general impoverishment of knowledge also in terms of diversity. It has already been documented, in the field of technological innovation, that from a social standpoint there is an excess of correlation between different R\&D policies (Bhattacharya and Mookherjee, 1986).

In the case of copyright, to borrow a definition from communication theory, we can speak of 'semiological reduction' (Baudrillars, 1972): the processes set in motion by the market trigger a dynamic which favours the emergence of particular types of ideas, i.e. those that are better equipped to answer the economic objectives. For example a strategy of risk minimisation will tend to move in this direction, because the uncertainty associated with preferences, and therefore with demand, will favour the production of similar ideas, i.e. those clustered around the taste currently in vogue.

Once again, the thesis is corroborated by the sociological literature which--starting with the seminal work of Adorno and Horkheimer (1947)--in fact denounces the products of cultural industries, pointing out their tendency to flatten out knowledge, creating a sort of pseudoindividuality which, behind an outward facade of minimal originality, in reality only bolsters conformity.

It is also reasonable to assume that, with respect to their use-value, intellectual works answer purposes that are not exclusively economic, but which fulfil the personal and collective utility functions of both their consumers and creators in a variety of ways ${ }^{19}$. As a consequence, the implicit assumption that individuals undertake the creation of ideas primarily to secure revenues is not only unproven, but widely contradicted by the anthropological, ethnographic, historical and even scientific literature (Dasgupta and David, 1994). In fact the arts, in their most disparate forms, have always existed in a variety of cultural contexts (David and Foray, 2002). This might prompt the objection that, precisely because creative activities are so deeply rooted in human nature and collective contexts, the continued creation of ideas with high use-value would nevertheless be assured, irrespective of the positive or negative effects of the market.

In response to this it should be pointed out that, over the long term, copyright mechanisms will have an impact even in this sphere. In fact, by favouring ideas that maximise expected profits, and transforming their beneficiaries into consumers, the right will also tend to alter the behaviours of both creators and consumers. As the market comes to prevail, the former may become more aware of, and influenced by, financial considerations, while the latter, continually 
exposed to market signals expounding the importance of intellectual works with high use-value, might alter their preferences accordingly ${ }^{20}$. This question has been explicitly investigated in the social sciences, where individuals have repeatedly been shown to be culturally 'malleable' (Marcel Mauss, 1979).

Consumers might also interpret the market success of products with high exchange-value as an indication of their high use-value, thereby generating a sort of ex-post equilibrium in which use-value and exchange-value coincide: however this is really only a consequence of the conditions artificially created by copyright. The described dynamic can ultimately lead to an opposite selection to that feared by supporters of intellectual property rights: only ideas with a high exchange-value are created, and these crowd out traditional preferences through the abovedescribed mechanism.

\section{Authors versus owners: the metamorphosis of the incentive}

Another peculiar attribute of copyright, that sets it apart from other intellectual property rights, concerns the separation between the sphere of authorship, which defines creative proprietorship, and that of ownership, which defines economic proprietorship. This (by no means self-evident) distinction injects ambiguity into the market of copyrighted works, by casting doubt, as we shall see, not just on the efficiency of the right, but also (once again) on the consistency between its stated ends and the means of achieving them.

The above distinction occurs in every copyright law, where all the national variants (though admittedly with differences in interpretation from country to country) break up the right into two components, moral rights and economic rights, which are treated as distinct entities and applied in different contexts (Metaxas-Maranghidis, 1995; Bently and Sherman, 2001).

The standard explanation for this division states that the purpose of moral rights is to protect authorship, that is to say the intimate bond between an author and his work, as a result of which they fall under the scope of natural rights, which are inalienable ${ }^{21}$. By so doing the legislators have sought to acknowledge and protect the extra-economic significance of creative activities. Pecuniary rights, on the other hand, protect ownership, i.e. the rights of economic exploitation of an intellectual work, and are perfectly alienable ${ }^{22}$.

Note that the intention of the legislation is that moral rights should temper the exploitation of pecuniary rights, in order to safeguard aspects that the latter are unable to protect. This, implicitly accepts the thesis that creative activities extend into spheres that the market is not always able to reach.

In any case, there is lively debate in the juridical literature on the role and applications of these two components of copyright, with no shortage of cases in which theoretical 
contradictions abound $^{23}$. Although these aspects are marginal for the purposes of this analysis, they contain an interesting parallel with the previously mentioned causal relation of exchangevalue to use-value. In fact here we have ownership (which gives the owner, or licence holder, the exclusive right to duplicate and sell the intellectual work) being granted to stimulate authorship. In other words, although the economic activity hinges on ownership, the profits which it secures for the holder of the right are intended to stimulate the creation of new copyrightable works--in essence new authorships.

So once again we see that the economic and creative dimensions, though theoretically distinct, are in practice placed on an equal footing, with the former being causal to the second. There have already been doubts expressed as to the validity of this position. But even setting this ambivalence aside, and assuming the incentive to be valid, the possibility of alienating economic rights raises serious questions as to the robustness of the mechanism: if authors, for whatever reason, are not the beneficiaries of the profits derived from the exploitation of their ideas, the incentive provided by copyright might not work.

Now it is reasonable to assume that creators generally operate outside the market, or at any rate that they are not perfectly informed about it, whereas their opposite numbers (publishers, record labels etc.) are as a rule better informed about the economic mechanisms, and therefore able to assign a specific probability distribution to the eventual 'success' of an intellectual work. What emerges, therefore, is a situation of asymmetric information, with creators at a disadvantage, that could potentially compromise the correct functioning of the incentive. In fact, because creators lack the adequate analytical tools, they are not in a position to calculate the real profits and might consequently undersell their rights. In such a case, the reward mechanism of copyright would fail to function (or do so in a distorted manner, attributing the profits to the wrong subjects), with the social costs of the monopoly still being incurred despite the prior alienation of the economic rights. Nor can we attribute any great significance to the inalienability and perpetual ownership of moral rights, because these cannot bring in economic benefits under the law.

It would therefore seem more logical, in pursuing the institutional objectives of intellectual property rights under conditions of uncertainty, to strengthen the position of authors--who are the weaker party in the negotiation--for example by allowing for the periodic renegotiation of transferred economic rights, which are the primary incentive of copyright. Such a clause might help correct the informational asymmetry that currently favours licence-holders, ensuring that more incentive-producing revenues reach creators, who in many cases are not the subjects truly rewarded by copyright ${ }^{24}$.

The above is indirectly backed up by the historical record: copyright and author's right were originally instituted for a very different purpose from the encouragement of creativity, and 
namely to protect the right to duplicate and sell copies of an idea, under a "utilitarian calculus that balances the needs of copyright producers [i.e., the publishers] against the needs of copyright consumers, a calculus that appears to leave authors at the margins of its equation" (Goldstein, 1996, pp. 168-169) $^{25}$.

The present day reapprais al of moral rights, which on the one hand offers a more solemn and almost ethical justification for copyright (all to the benefit of stakeholders, and very rarely of the authors), on the other hand reflects a certain reluctance, on the part of legislators, to treat

copyright as a purely economic matter ${ }^{26}$. In any case, the fact that the moral rights of authors (or their heirs) are exercised chiefly outside the market--because monetary claims cannot be advanced on the basis of moral rights--puts their effectiveness and, as mentioned previously, their true significance, very much in doubt.

\section{The right and the market: a dialectical relationship}

A rapid overview of the competitive dynamics can further contribute to an economic analysis of copyright, its workings on the market and the outcomes in terms of efficiency. In effect, the majority of the literature on this subject focuses on a static analysis of the market of ideas, and therefore treats the right as an instrument 'within the market': given a particular set of initial conditions, either with or without an ex-lege monopoly, equilibria are identified and the outcomes in terms of welfare are compared. This exercise in comparative statics therefore assumes that there exists an unchanging market to which the different systems can be applied, in order to add up the various profits and consumer surpluses and compute the resultant social welfare outcomes (Landes and Posner, 1989).

It does not, however, take into account the dynamic effects of the right on the behaviours of economic agents and on the market structure itself, and the not negligible fact that it gradually alters the scenario under study.

\subsection{Market structure and rational behaviours}

The effects of copyright are not limited, ceteris paribus, to averting market failure, because it also progressively alters the structure of the market and behaviours, producing outcomes that are inconsistent, and often widely at variance, with its purported aims. For example, some observers (OECD, 1995; Fels, 1994) have noted that, in the recording, publishing and software industries (but also in chemicals and pharmaceuticals), firms have repeatedly leveraged their exclusive intellectual property rights to elevate trade barriers against parallel imports, with the clear aim of pursuing international price discrimination. In the case in point it was observed that (OECD, 1995, par. 5 and par.2) -“[...] the copyright law goes further than correcting that market failure 
in also restricting the distribution of a copyrighted product, validly on the market consistent with copyright law in its country of origin" and there are "[...] two possible explanations for this state of affairs, that regulation [in imports] is in the public interest or that legislature has been "captured" by producers of copyrighted material".

In the above-described situation intellectual property rights have thus been shown to promote anti-competitive behaviours, with the obvious negative repercussions on collective welfare. This is on no account a paradoxical phenomenon, and has a very simple explanation: because copyright attributes de facto market power, it is rational for owners to seek to exploit this to the full, for example by practicing international price discrimination designed to extract maximum surpluses from consumers, even if this clearly undermines the welfare-enhancing purpose of the law. And yet in economic terms, from the perspective of the copyright owner, such behaviours are perfectly rational--and in the majority of cases legitimate (Ramello, 2003).

What is more, the economic theory of rent-seeking tells us that incumbent monopoly-holders will generally have a rational tendency to make unproductive investments directed at maintaining their dominant position: an activity that "destroys value by wasting valuable resources" "(Tollison and Congleton, 1995, p. xii). The limiting case, in this respect, would be that where the rent-seeker dissipates all the monopoly revenues ${ }^{27}$. Such an outcome is clearly at odds with the efficiency objectives of the intellectual property legislation.

\subsection{The dilemma of competition}

The points described thus far paint an ambiguous picture: because copyright is an exclusive right, it injects a monopolistic drift into the market that will be more or less pronounced depending on the market power that the owner is able to command (Ramello 2003). This drift may blur the existing margins between competitive and anticompetitive behaviours, and is clearly a source of inefficiency.

The analysis takes its cue from the controversial Magill case, and from the more recent $\mathrm{IMS}^{28}$. In both suits, the exclusive rights granted under copyright were in fact judged to be illegitimate under the antitrust laws, because they had the effect of barring potential competitors from the market. Now, from an economic perspective the question is contradictory: if we accept the rationality hypothesis, then within any given regulatory framework behaviours will be consistent with the profit-maximisation objective. Therefore, if an individual is granted a legal monopoly, it is perfectly rational for him to seek to translate it into an economic monopoly, and to endeavour to retain it. This behaviour will be anticompetitive only to the same extent that the copyright law itself is--in practice, albeit not in its original intention--anticompetitive. For goods that are sufficiently differentiated and poorly interchangeable (such as ideas), ownership of an exclusive right does in fact result in a monopoly, because it restricts access to a fundamental 
input. It would therefore be irrational to expect copyright holders to behave in a manner inconsistent with this framework.

And in fact, if we can say that copyrightable works in many cases have a naturally imperfect interchangeability (because every idea is in some way different from the others), it becomes rational for owners to pursue a strategy of accentuating this attribute, by widening the real or perceived distinction between competing products. This approach, of shifting competition onto non-price elements, is manifestly aimed at attenuating price competition, and will have a correspondingly anticompetitive effect, with the attendant inefficiency ${ }^{29}$.

The tools for pursuing the above strategy are provided by the mass media, which are able at the same time to reach vast audiences repeatedly exposing ideas until they become universal signs, and to make every cultural product unique and non-interchangeable. Through the combined workings of these economic and technological mechanisms, the uptake of an idea becomes increasingly equated with its market success. Thus, thanks to the communication media, exchange-value becomes causal with respect to use-value.

In other words, the market success and relentless media exposure of an idea trigger a self enforcing mechanism that tends to augment its uniqueness and desirability. The result is a sort of 'perceived quality' or 'perceived uniqueness' in the eyes of consumers, that increases roughly in direct proportion with notoriety and success.

So that, ultimately, the logic of the market drives toward ever increasing (unproductive) investments aimed at affecting this factor: for example high expenditure on marketing and special effects, huge sums paid to artists, entertainers, actors, etc. All this can increase the quality and uniqueness perceived by consumers, the rigidity of demand and, ultimately, the volume of revenues. However these types of investments are a move in the direction of rentseeking behaviours, which makes them, at least to some extent, anticompetitive and inefficient.

The competitive game between copyrighted works is essentially played out on the definition of their quality and uniqueness as it is perceived by consumers, which can at times be artificially enhanced or even artificially constructed. This sets in motion a sort of recursive, positivefeedback mechanism between exchange-value and use-value, that ultimately serves to maximise the profits of producers, with the additional consequence of aggravating the net loss due to monopoly (Silva and Ramello, 2000).

What is more, this mechanism shifts the industrial configuration toward a so-called 'winnertakes-all' market model (Frank and Cook, 1995): the investments sunk for differentiating products become more and more like purchasing a lottery ticket, with an increasingly slender chance of winning an ever bigger jackpot ${ }^{30}$.

We therefore have, on the one hand, high expected profits for a few players which tend to skew expectations, attracting an above-optimal number of individuals and investments, with a 
resultant waste of resources; and on the other hand a rewards system that marks a sharp division between winners and losers, where in reality a continuous quality spectrum exists (Frank and Cook, 1995). So that, as a result of this market structure, ideas that are only marginally inferior to the winners in terms of quality will fail to succeed.

A dynamic such as this impoverishes both society and cultural diversity. And most importantly, it by no means guarantees the correct functioning of the incentive to create: "[...] in an economy permeated by these markets, there can be no general presumption that private market incentives translate self-interested behaviour into socially efficient outcomes" (Frank and Cook, 1995, p. 20).

This once again confirms the hypothesis of the dynamic effects of the right on the market structure. The lottery logic in fact drives incumbents to pursue behaviours aimed at increasing their likelihood of winning, by elevating barriers to entry that limit the number of possible competitors-winners and acquiring a large number of 'tickets'. Both behaviours are essentially an updated version of the dissipation of monopoly quasi-rents. In the first case, there is an endogenous escalation of certain costs (e.g. marketing, distribution and even production expenditure, as in the case of expensive special effects or high salaries for actors, etc.), which become the focal point of competition, restricting the field of competitors to only those able to sustain such costs ${ }^{31}$.

In the second case, high diversification and the accumulation of large catalogues of copyrighted works increases the likelihood of winning, under the rationale of minimising risk (Ramello, 2003). Overall, however, the described dynamic consolidates the position of incumbents and further restricts competition, gradually increasing the concentration of industries, as has been confirmed by surveys of specific sectors ${ }^{32}$.

The situation therefore favours the emergence of players with strong market power, further enhanced through the continual acquisition of complementary sectors in the fields of information, entertainment and communications. The optimal strategy has been eloquently described by the former president of a large industrial conglomerate: "When power is moving between different bits of the value chain, you need to own the whole chain" (Anonymous, 1998).

\section{Structure of copyright and its objectives}

To further evaluate the impact of copyright on the market, it is necessary to analyse its structure: in fact, an efficient incentive needs to have a particular architecture. In the case in point, this requires proper handling of the instrumental variables involved: deciding what to protect (the 'scope' of the right) and for how long to protect it (the 'duration' of the right) are 
fundamental decisions in the design of the incentive mechanism. An exaggerated level of protection could cause excessive losses in terms of social welfare, and even compromise innovation by blocking the cumulative creation process (Scotchmer 1998, David 1993). On the other hand a form of protection that is too weak, according to the standard approach, could lead to market failure.

\subsection{Consistency of the incentive}

The reference value, as emerges from the economic literature on patents, is the costs that are incurred in creation: because the incentive is necessary for recouping these costs, it must be calibrated on this basis (Scotchmer, 1998). Assuming therefore that a creator acts as an agent of the society, the incentive will have to satisfy the usual participation and compatibility constraints, which are strictly dependent upon costs ${ }^{33}$. However copyright fails to take these aspects into account, and provides structurally equivalent protection to a multitude of different ideas that all have different creation costs. As a consequence, it seems doubtful that it can correctly function as an incentive.

A much more likely situation in this scenario is that some producers of inefficient ideas will nevertheless receive an incentive, but that (because only successful copyrighted works cover the costs incurred) negative expectations will later arise, leading to subsequently lower investments on the part of those who fail to achieve market success after a certain amount of time ${ }^{34}$. This could be equally detrimental to those creative activities that require a longer time period to become successful.

Finally, only a right that is diversified according to creative domains and types of ideas can efficiently balance the needs of creators, who are given an incentive by the right, with those of consumers, who are rationed by the right ${ }^{35}$. However in the domain of copyright equal protection is given to a vast assortment of ideas which do not all, or not in equal measure, contribute to the welfare function. We are therefore justified in asking, once again, to what extent such a blind mechanism is effectively able to protect collective interests.

\subsection{Scope}

Looking at the individual instrumental variables, the scope and duration of the right, there are other questions that arise. It is a commonly held view that, in the case of copyright, the first variable is negligible, because--it is claimed--the right does not protect ideas in the abstract but only their expression, i.e. fixing in a tangible medium, and hence the scope is determined by this same fixing ${ }^{36}$. 
In reality, this assertion can be challenged in a number of ways and takes a rather shortsighted view of creative processes. Some authors (Jones, 1990, p. 552 and 552) argue that the conceptual dichotomy may be sterile: " no <<expressionless idea〉> exists" because "any $<<$ idea >> must necessarily have an expression". In addition, the " distinction between the terms $<<$ idea >> and <<expression>> cannot serve as a fundamental determinant for deciding what is protectible under copyright law" (Jones, 1990, p.552). And, in fact, the scope depends on the law which defines what constitutes the subject matter. Consider in this respect the case of a musical piece: legislators generally give most importance to the melody, permitting third parties to imitate the orchestration, arrangements, and so forth, even though these are clearly identifiable elements that account for a substantial-or even prominent--part of the compositional effort ${ }^{37}$. Strictly speaking, in fact, the decision to protect one specific element rather than another will have consequences on what is created, due to the clear demarcation that is made between what can and cannot be copied.

Another aspect also needs to be considered: the extension of copyright to the most disparate contexts has, in terms of competition, had a similar effect to the extension of scope in the domain of patents. If the incentive of a patent depends on what is understood by the definition

of 'idea'--which delimits the bounds of the monopoly ${ }^{38}$--the incentive of copyright depends on what we accept to be an 'expression of an idea'. In the above-mentioned Magill and IMS cases, for example, the extension of copyright to objects that have little or no bearing on creativity, such as a television listing or a database, while it might provide a perhaps modest incentive to create, also encourages behaviours detrimental to competition.

\subsection{Duration}

An examination of the second instrumental variable, the duration of the right raises further questions as to the efficiency of the institution. Even if we accept, for simplicity's sake, that scope is of little importance in the copyright case, this is all the more reason for duration to become the crucial variable through which legislators balance out the trade-off between private incentive and collective welfare.

A correct duration, under the logic of incentive, is that which grants creators revenues at least equal to the costs incurred, and this value needs to be determined on a case by case basis. In general, though, the time horizon should always be defined in a manner that permits calculation of the correct expected profits, while the attribution of a long post mortem autoris term (PMA), which shifts the duration well beyond the lifetime of the creator, remains a dubious proposition.

In effect in the EU the duration can be as high as 70 years PMA (Duration Directive 93/98/EEC)--exceeding the already substantial 50 year term set by the Berne Convention--while 
in the US the Copyright Term Extension Act (CTEA, 1998) has extended the duration to 70 years PMA for private individuals, or to 95 years if the owner of the right is a firm. Now these durations make it rather difficult to compute the expected benefits, so that there is a danger of merely extending the quasi-rents to the detriment of market efficiency. In particular, there is the risk of hampering incremental creative activities whose access to knowledge will be rationed by a very long duration ${ }^{39}$, whereas accomplishing the ultimate aim of copyright--namely the creation of new knowledge accessible to society through provision of a temporary private benefit--would require minimising this exclusion effect which should certainly not extend beyond the creator's lifetime.

Moreover, the trivial assertion that "that a longer term of protection is necessary for them [copyright owners] to recoup their original financial outlay "(Antill and Coles, 1996, p. 380) is unacceptable, because firms and managers rarely calculate even their longest term investments over such extended time horizons.

In short, the necessity of assuring revenues over such a protracted time period (nearly perpetual from the perspective of economic agents) finds no support in the economic theory, but can instead be plausibly explained as a successful capture of law-making processes by economic interest groups, who have in this way, aided and abetted by the authorities, effecting a fullfledged and permanent expropriation of public goods (i.e. knowledge) from society, with the illconcealed aim of creating solid intangible assets for themselves (David, 2000, Ryan 1998). The clear consequences of this operation, which has little to do with the authors themselves (or with their heirs), are an increased cost to society, wasted resources (through the dissipation of quasirents) that could otherwise be used elsewhere, restriction of access to information, and impoverishment of the cultural domain.

\section{Regulatory process and 'capture'}

The issue of interference on the part of economic stakeholders requires at least a brief digression. The ostensible goal of copyright and author's right is to increase knowledge by providing an incentive to creators. From a historical perspective, though, we find that the sources of the laws are very different: the right originated as a privilege granted to publishers, and was often used by governments as a tool for controlling what was published (Goldstein 1994, Patterson, 1968). Subsequently various attempts were made to introduce corrections favouring authors, but powerful interest groups have continued to exert considerable influence over its evolution.

Moving on to recent times, we find that the national and international law-making processes have been at the very least distorted, if not steered wholesale, by intensive lobbying campaigns of economic interest groups and the resultant political pressures exerted by certain governments. 
The most active nation in this respect has been the United States (the leading exporter of intellectual property), which through its US Trade Representative has, beginning in the mid 1980s, insisted on incorporating into GATT specific agreements relating to intellectual property (Ryan 1998). In this connection, Christie (1995, p.527) asserts in no uncertain terms that " the US obsession with obtaining 'international harmonisation' of intellectual property laws $[\ldots]$ in real terms means the adoption of law satisfactory to the interests of US enterprises"

Irrespective of opinion on this matter, the pressures exerted led to the 1994 drafting and ratification, in Marrakesh, of the Agreement on Trade-Related Aspects of Intellectual Property Rights (TRIPs). This has had a considerable impact on the national laws, first and foremost among these those of the European Community, further stimulated by the concomitant pressures of economic interest groups. Antill and Coles (1996, p.379) have underlined its role: "A protracted period of lobbying and industry investigation culminated on 20 November 1995 with the laying before Parliament of a draft Statutory Instrument entitled 'The Duration of Copyright and Rights in Performances Regulations 1995'. This Statutory Instrument amends the existing Copyright, Designs and Patents Act 1988 ('CDPA') and implements into national law the EC Directive 93/98 EEC, colloquially known as the 'Duration Directive"”.

What emerges, therefore, is a clear impression, backed by a growing number of observers (Christie, 1995; Altbach, 1996; Ryan, 1998; Lessig, 2001), that the evolution of copyright laws is today determined by a complex dynamic, in which the pressures of special interest groups play a significant and prominent role. So it is unlikely that the development of these laws, driven by political negotiation, can best serve the public objectives of the right, and the goal of efficiency.

\section{Conclusions}

The stated objective of copyright relates to the public domain: the production of new knowledge through the private stimulation of creativity. Even if the resultant commodification of ideas, bolstered by the ex-lege monopolies, does encourage creative activities, it also has various other consequences. First of all, it can influence the types of ideas that are produced, and limit their diversity. Secondly, it can favour rent-seeking economic behaviours which have a negative impact on efficiency. Finally, due to its peculiar structure, it does not fully answer the logic of incentive and can produce results very different from those intended, and which are not necessarily efficient.

Copyright does have the obvious but crucial effect of rationing demand, so that a considerable portion of potential consumers are excluded through price selection, with a detrimental effect on incremental knowledge creation. This exclusion effect should in theory be minimal--only in order to give a reward to creators for their contribution to society--whereas 
under the present structure of the right it is excessive. And the current regulatory trend is toward further augmenting it. In fact the recent history of copyright protection laws has shown that this often indiscriminate extension is a response to powerful lobbying forces, which by their very nature serve private interests.

What is more, sector surveys have detected, over the past few decades, an increasing concentration of intangible assets in the hands of a limited number of subjects, who are gaining more and more control over creative activities and the dissemination of knowledge. This concentration, as we know from industrial economics, can interfere both with competition and with innovative processes.

Summing up, therefore, copyright today does not seem able to pursue the public goals that justify its existence, although it certainly does succeed in serving private interests. The former are, at best, manipulated in order to achieve the latter. This, essentially, is the message of the Latin motto of the title. 


\section{References}

Adorno T. e Horkheimer M. (1947, edition 1979), Dialectic of Enlightenment, Verso, London.

Altbach P.G. (1996), 'The Subtle Inequalities of Copyright',The Acquisitions Librarian, 15, 1726.

Anonymous (1998), 'Wheel of Fortune. A Survey of Technology and Entertainment', The Economist, November $21^{\text {st }}, 1-21$.

Antill J. e Coles P. (1996), 'Copyright Duration: The European Community Adopts 'Threee Score Years and Ten', European Intellectual Property Review, 18, 379-383.

Arrow KJ. (1962), 'Economic Welfare and the Allocation of Resources for Invention, in Nelson R.R.(ed.), The Rate and Direction of Inventive Activity, Princeton University Press, Princeton.

Arthur W. B. (1988), "Competing technologies: an overview", in Dosi G. et al. (a cura di), Technical change and economic theory, Pinter.

- (1989), "Competing technologies, increasing returns and lock-in by historical events", Economic Journal, 99, 116-131.

Audretsch D.B. (1997), 'Technological Regimes, Industrial Demography and the Evolution of Industrial Structures', Industrial and Corporate Change, 6, 1, 49-81.

Baudrilllard J. (1972), Pour une critique de l'économie politique du signe, Gallimard, Paris.

Bently L. and Sherman B. (2001), Intellectual Property Law, Oxford University Press.

Besen S.M. (1998), 'Intellectual Property', in Newman P. (ed.), The New Palgrave Dictionary of Economics and the Law, Macmillan, London.

Bhattacharya S. e Mookherjee D., (1986), 'Portfolio Choice in Research and Development', Rand Journal of Economics, 17, 594-605.

Christie A. (1995), 'Reconceptualising Copyright in the Digital Era', European Intellectual Property Review, 11, 522-530.

Coase R. (1960), 'The Problem of Social Cost', Journal of Law and Economics, 3, 1-44.

Dasgupta P. and David P. (1994), 'Towards a New Economics of Science', Research Policy, 23, 487-532.

David P. (1985), "Clio and the economics of QWERTY", American Economic Review, 75, 2.

David P. (1993), 'Intellectual Property Institutions and the Panda's Thumb.Patents,Copyrights and Trade Secrets in Economic Theory and History' in Wallerstein M. B., Mogee M. E., and Schoen R. A. (eds.), Global Dimensions of Intellectual Property Rights in Science and Technology, National Academy Press, Washington DC.

David P.A. (2000), 'The Digital Technology Boomerang: New Intellectual Property Rights Threaten "Open Science" ', World Bank Conference Volume (forthcoming).

David P.A. and Foray D. (2002), 'An Introduction to the Economy of the Knowledge Society', International Social Science Journal, 54, 171, 9-23.

Fels A (1994), Compact Discs. Intellectual Porperty Rights and Competition Policy, DAFFE/CLP(94)18, OECD, Paris.

Foray D. (1989), "Les modéles de compétition technologique: une revue de la litterature", Revue d'économie industrielle, 48. 
Frank R.H. e P.J. Cook (1995), The winner-take-all society, Free Press, New York.

Geertz C. (1973), The Interpretation of Cultures, Basic Books, New York.

Goldstein P. (1994), Copyright's Highway, Hill and Wang, New York.

Gordon W. J. e Bone R.G. (1999), 'Copyright', in Bouckaert B. e De Gest. G. (eds), Enciclopedia of Law and Economics, Elgar, Cheltenham-Northampton.

Griffiths P. (1994), Modern Music. A Concise History, Thames and Hudson, London:

Hodgson G.M. (1988), Economics and Institutions, Polity Press, Cambridge.

Hong H. (2000), 'Marx and Menger on value: as many similarities as difference', Cambridge Journal of Economics, 24, 87-105.

Isaac R.M. e Walker J.M. (1998), 'Nash as an Organizing Principle in the Voluntary Provision of Public Goods: Experimental Evidence', Experimental Economics, 1, 191-206.

Jha R. (1998), Modern Public Economics, Routledge, London.

Jones R.H. (1990), 'The Myth Of The Idea/Expression Dichotomy in Copyright Law, Pace Law Review, 10, 3, 551-607.

Landes W.M. e Posner R.A. (1989), 'An Economic Analysis of Copyright Law', Journal of Legal Studies, 18, 325.

Lessig L. (2001), The Future of Ideas, Random House, New York.

Levin R.C., Klevorick A.K., Nelson R.R. e Winter S.G. (1987), 'Appropriating the returns from industrial research and development', Brookings Papers on Economic Activity, 3, 783-820.

Marvasti A. (2000), 'Motion Picture Industry: Economies of Scale and Trade', International Journal of the Economics of Business, 7, 1, pagg. 99-114.

Mauss M. (1979), Sociology and Psicology, Routledge and Kegan Paul, London.

Metaxas-Maranghidis G. (ed, 1995), Intellectual Property Laws of Europe,Wiley, Chichester.

Monopolies and Mergers Commission (1994), The supply of recorded music, HMSO, London.

OECD (1995), Annex to the Summary Record of the $66^{\text {th }}$ Meeting of theCommittee on Competition Law and Policy, Mini -Roundtable on Compact Disks. Intellectual Property Rights and Competition Policy, DAFFE/CLP/M(94)2/ANN2, OECD, Paris.

Patterson L.R. (1968), Copyright in Historical Perspective, Vanderbilt University Press, Nashville

Ramello G.B. (2003), 'Copyright and Antitrust Issues', in Gordon W. E Watt R. (eds), The Economics of Copyright: Developments in Research and Analysis, Elgar, CheltenhamNorthampton.

Ramello G.B. (2004 forthcoming), 'Intellectual Property and the Market of Ideas', in Backhaus J. (ed) Elgar Companion in Law and Economis, Second Edition, Edward Elgar, CheltenhamNorthampton.

Rushton M. (1998), 'The Moral Rights of Artists: Droit Moral ou Droit Pécuniare ?', Journal of Cultural Economics, 22, 15-32.

Ryan M.P.(1998), Knowledge Diplomacy: Global Competition and the Politics of Intellectual Property, Brookings Institutions Press, Washington D.C.

Scotchmer S. (1998), 'Incentives to Innovate', in Newman P. (ed.), The New Palgrave Dictionary of Economics and the Law, Macmillan, London.

Schumpeter J. (1943), Capitalism, Socialism and Democracy, Unwin University, London. 
Silva F. e Ramello G. (2000), 'Sound Recording Market: the Ambiguous Case of Copyright and Piracy', Industrial and Corporate Change, 9, 3, 415-442.

Silva F. e Ramello G. (1999), Dal vinile a Internet: Economia della Musica tra Tecnologia e Diritti, Fondazione Giovanni Agnelli, Torino.

Siwek S.E. (2002), Copyright Industries in the U.S. Economy. The 2002 Report, International Intellectual Property Alliance, Washington DC.

Solow R. (1957), 'Technical Change and The Aggregate Production Function', Review of Economics and Statistics, 39, 312-320.

Strowel A. (1993), Droit d'auteur et copyright, Bruylant, Bruxelles e L.G.D.J., Paris.

Tollison R. D. e Congleton R. D. (eds) (1995), The Economic Analysis of Rent Seeking, Elgar, Aldershot.

Towse R.(1996), Economics of Artists' Labour Markets, ACE Research, Report N.3, Arts Council of England, London.

Towse R. (1999), 'Incentivi e redditi degli artisti derivanti dal diritto d'autore e diritti connessi nell'industria musicale', in Silva F. e Ramello G. (1999).

Varian H.R. $\left(1992^{3}\right)$, Microeconomic Analysis, Norton \& C., New York. 


\section{Notes}

Università Carlo Cattaneo - LIUC, Castellanza, Italy. Contact: gramello@liuc.it

Forthcoming in Josselin J.J. and Marciano A. (eds) Law and the State. A Political Economy Approach, Elgar. I am grateful to Juergen Backhaus, Christian Barrère, Bruno Frey , Sophie Harnay, Simon Luechinger, Jean-Michelle Josselin, Alain Marciano, Antonio Nicita, Ahmed Silem, Francesco Silva, Frank Stephen and Michael Wolgemuth for the helpful remarks and comments. The usual disclaimer applies.

See for example Goldstein (1994) and Ramello (2004).

2 The discussion that follows applies without distinction to both the copyright of common law systems and to author's rights and neighbouring rights, its juridical equivalent in civil law systems. Although not all observers agree in considering these two legal institutions to be equivalent, the generalisation does not invalidate the arguments for this economic analysis. And it is also true that the various national laws have been tending to significantly converge, under the thrust of endogenous market forces--i.e. growing internationalisation and integration (see Goldstein, 1994; Monopolies and Mergers Commission, 1994). Strowel draws an interesting critical parallel (1993, p. 658), which underlines the evolutionary dialectic between these two juridical systems and notes how elements of each can be detected in the other.

Since 1996, for example, the category of copyright protected goods occupies first place in the United States balance of trade (see < http://www.iipa.com/> and Siwek, 2000).

${ }_{5}^{4}$ This does not, of course, rule out any extra-economic reasons.

5 We recall that copyright does not protect ideas in the abstract, but only their fixing in a tangible medium, in other words the "expression of an idea" (see Bently and Sherman, 2001). This peculiarity will be examined subsequently; whereas for the purposes of the present economic discussion, the term "ideas" shall be understood to also denote their expressions.

${ }^{6}$ Note how this is not the only possible solution for overcoming the market failure in the case of public goods. For an overview of the alternatives, see for example Jha (1998, ch. 4).

7 See among many others, Arrow (1962), Landes and Posner (1989) and, for a rapid overview, Audretsch (1997).

${ }^{8}$ However this hypothesis is not substantiated. And on the contrary, experimental economics has found that, in many cases, public goods are produced even where the predictions of non-cooperative equilibrium would indicate the opposite (Isaac and Walker, 1998).

${ }^{9}$ See for example Levin, Klevorick, Nelson and Winter (1987, p.816)

${ }^{10}$ However the hypothesis has not been clearly verified.

${ }^{11}$ Scotchmer (1998, p. 273) also maintains that "patents are a very crude incentive mechanism with many pernicious side effects".

${ }^{12}$ Communication theorists would more correctly replace the term 'use-value' with 'symbolic exchangevalue', when speaking of the dynamics of social relationships (Baudrillard, 1972). For the sake of simplicity, we shall here continue to define the term use-value as denoting all those socially and individually-determined values that cannot be described in purely monetary terms.

${ }^{13}$ The dichotomy between these values, which has inspired impassioned pages in the history of economic thought, can be traced back to the classical tradition, that we shall not be discussing here. The central idea, already put forward by both Marx and Menger (see Hong, 2000), is that value is not a natural property of goods, but rather exists in the social domain, in the sense that it is defined by relationships between human beings. Now, such relationships can be economic, in which case they generate an exchange-value, but they can also extend far beyond the purely economic sphere (and in this, for example, we diverge from the strict Marxian interpretation).

In the cultural sphere at least, and with all due respect to absolute proponents of neoclassical positions, the existence of values that are not purely economic has been verified by anthropological and sociological studies (beginning with Boas, 1938 )

14

On the shared and social nature of knowledge, see Geertz (1973).

${ }^{15}$ Geertz (1973, p.11) asserts that "culture is public because meaning is". 
See Ramello (2003).

${ }^{17}$ To further clarify this idea, consider the possibility of producing electrical energy using either a green technology or a highly polluting but cheaper method. An entrepreneur faced with a long-term decision will obviously not consider the negative externalities, and prefer the more profitable but polluting technology, unless of course the structure of private costs is altered by some form of public intervention.

It is no coincidence that one of the first cases of on-line copyright protection arose precisely in this sphere: Playboy Enters v. Chuckleberry Publ., Inc. 939 F. Supp. 1032 (S.D.N.Y. 1996), recons. Denied, 1996 U.S. Dist. LEXIS 9865 (S.D.N.Y. 1996).

${ }^{19}$ This can be said to apply, for example, in the Western scientific community, in which fame, the respect of colleagues and so forth often take precedence over financial considerations, in the utility functions of academics (Dasgupta and David, 1994). In point of fact, the tastes and preferences of individuals are not exogenous, as neoclassical theory would frequently have it, but endogenofus (Hodgson, 1988, pp. 13-sgg).

${ }^{21}$ Moral rights, which originated in civil law jurisprudence, have today also been incorporated into common law systems. They protect the right of publication, the right of integrity and the right of paternity (Bently and Sherman, 2001).

${ }^{22}$ They take the form of a bundle of rights for each possible form of economic exploitation (right of reproduction, right of distribution, etc. ; Bently and Sherman, 2001).

See for example Rushton (1998) and Strowel (1993). In the US doctrine of work-made-for-hire, for example, the employer is considered to be the author and hence acquires all the rights, in defiance of the concept of an intimate bond between creator and work.

${ }^{24}$ This observation is borne out by empirical evidence (see Towse, 1996 and 1999).

${ }^{25}$ The same opinion is expressed in David (1993) and Strowel (1993).

On the possibility of undue manipulation of authorship see Strowel (1993, p.668(: "[...] it is well-known that, under the banner of author's rights, publishers have from the outset sought to pursue their own interests, with increasing success the more they are able to officially lay claim to prerogatives on behalf of creators... and have these transferred to them by contract".

27

${ }^{27}$ David (1993) concurs with this view, for the case of patent.

${ }^{28}$ Magil case, Radio Telefis Eireann (RTE) v. Commission of the European Communities (C-241/91 P e C242/91P, April 6, 1995); COMP D3/38.044. IMS Health v. NDC Health, European Commission, 3/7/2001, COMP D3/38.O44

29

For an in-depth discussion see Silva and Ramello (2000) and Ramello (2003).

${ }^{30}$ This is borne out by empirical surveys on copyright revenues (Towse, 1996 and 1999).

31 As we can see, therefore, certain investments have the two-fold consequence of reducing the replaceability of certain ideas while at the same time elevating barriers to entry.

32 See for example, Marvasti (2000) for the film industry and Silva and Ramello (2000) for the recording industry.

${ }_{34}^{33}$ For a presentation of the principal-agent model see Varian (1992 3 , Chap. 25).

${ }_{35}^{34}$ See Scotchmer (1998)

${ }^{35}$ Altbach (1996, p.18) indirectly responds to this question: "It is time to take a step back from rampant commercialism to examine the complex world of copyright and the distribution of knowledge. There is, in reality, a difference between a Mickey Mouse watch, a Hollywood film, or even a computer software program, on the one hand, and a scientific treatise, on the other [...]Those who control the distribution of knowledge treat all intellectual property equally and are perfectly happy to deny access to anyone who cannot pay".

${ }^{36}$ For example Besen (1998, p.479) says: "The fixation requirement serves the obvious purpose of defining the scope of the claimed protection in objective terms".

37

Confirming this, the American musicologist Paul Griffiths (1994, p.9) speaking of the French composer Claude Debussy, said: "As for colour, Debussy was a master of delicate orchestral shadings, and pioneer in consistently making instrumentation an essential feature of composition. [...] Thus the orchestration has its part in establishing both ideas and structure; its more than an ornament or a means for enhancing rhetoric" (my italics). 
38

It is one thing to grant a patent to an electrical lighting system, but a very different one to say instead that the patent protects the idea of a light bulb, or of a carbon filament light bulb, etc. Clearly, the scope sets the bounds of competition.

Considering that an intellectual work is created in vita, its total revenues (in vita + post mortem) will have a duration of at least 100 years. 